\title{
Niklas Luhmann and Cybernetics
}

\author{
Michael Paetau \\ Center for Sociocybernetics Studies, Bonn, Germany \\ michael.paetau@sociocybernetics.eu
}

\begin{abstract}
Even though Niklas Luhmann himself never declared his own approach as a cybernetic one, and even if the relationship between systems theory and cybernetics is still not clearly defined in every way, it seems to be legitimate to classify Luhmann's Theory of Social Systems into the field of cybernetics approaches, more precisely as a socio-cybernetic one. Beside the concept of autopoiesis by Maturana and Varela there are various systems thinkers and cyberneticists like Wiener, Ashby, Shannon, Bateson, von Foerster who influenced Luhmanns work deeply. Certainly he fits the cybernetic principles into his theory rather idiosyncratically and partly after some significant revisions, but one can argue that Luhmann's Theorie of Social Systems is the conclusion of a confrontation of the mayor issues of cybernetic discourse with the European philosophical tradition. In the following article it is discussed the question in what extent we can include Luhmann's work into the cybernetic tradition. Which are the significant connection-points between cybernetics and Luhmann's work? What is the relevance of this connection for Luhmanns own theoretical development? Which are the congruences and which are the differences? To what extent is Luhmann's Theory of Social Systems even though his critical distance - integrable into the spectrum of the approaches of "New Cybernetic" (as Geyer \& van der Zouwen formulated in 1986)? After a short discussion on what is characterizing a theory as a cybernetic one, the article reconstructs Luhmann's critical debate on the most important theoretical problems of cybernetics and finally it will sketch out Luhmanns answer to this debate, which he gives in his own concepts. For Luhmann the fascination of cybernetics consists in explaining the problem of constancy and invariance of systems in a highly complex and dynamical world by observing communication processes. This makes cybernetics to a definitive non-ontological approach and brings it near to the functionalistic sociology.
\end{abstract}




\section{Introduction}

Opting for a cybernetic approach in research means accepting a number of fundamental principles that are not always unambiguously defined in literature but can be best described as a particular mode of thought, as a paradigm, or - as Gordon Pask once put it - as an art, philosophy or also a way of life ${ }^{1}$. While mathematician Norbert Wiener stresses the aspects of control and communication in natural science and humanities contexts, neurophilosopher Warren McCulloch defines cybernetics as an epistemology dealing with the generation of knowledge by communication. Management consultant Stafford Beer regards cybernetics as the science of organisation. To Ludwig von Bertalanffy, cybernetic systems are a special case of systems differing from other systems by the principle of selfregulation (Bertalanffy 1968, p. 17). As a scientific discipline, cybernetics distinguishes itself by concentrating on the research of control mechanisms, basing its activities on information and feedback as key concepts. ${ }^{2}$ Walter Buckley formulates the context in a similar manner by regarding concepts such as information, communication, cybernetics, self-regulation and self-organisation as well as adaptability as sub-areas of general systems theory (Buckley 1998, p. 3). Systems theory is understood here not so much as a uniform theory but more as a theoretical framework and a set of methodological tools that can be applied in different fields of research.

What is highly significant and is again and again pointed out by all authors is that cybernetics cannot be restricted to a special field of research objects. This meta-disciplinary view and its interdisciplinary options for application would already suffice to distinguish cybernetics in an academic world that is still characterised by the theoretical and methodical dualism of natural sciences and the humanities. Similar fundamental principles of organising individual elements as a systemic whole can be found in organisms, in society, and in technical artefacts. In the first chapter of "An Introduction to Cybernetics", Ashby writes that cybernetics "treats not things but ways of behaving. It does not ask 'What is a thing?' but 'What does it do?'” (Ashby 1957, p. 5). Biologist Humberto Maturana expresses this in a similar way in his answer to the question of life. According to Maturana, the question of life cannot be answered by seeking the necessary properties of the elements constituting living organisms, but by tracing the fundamental organisational

\footnotetext{
${ }^{1}$ Cf. Heinz von Foerster's discussion with Bernhard Pörksen for the journal Telepolis http://www.telepolis.de/deutsch/special/robo/6240/1.html (15.04.1998)

2"The theory of open systems is a generalized kinetics and thermodynamics. Cybernetic theory is based on feed-back and information." (Bertalanffy 1968, p. 150). However, this distinction gives rise to a number of problems, which above all come to the fore with the issue of the closedness or openness of systems. This will be discussed in more detail in Section 2.3.
} 
principles in which "living systems" acquire their identity and through which living systems differ from non-living systems. ${ }^{3}$

In his Theory of Social Systems, Niklas Luhmann refers to cybernetic principles in various contexts without characterising his approach itself as cybernetic or sociocybernetic. Nevertheless - and this is my proposition, which I wish to explore in the following - Luhmann's theory can indeed be assigned to the field of socio-cybernetic approaches, albeit with a number of peculiarities. What fascinates Luhmann about cybernetics is that the problem of constancy and invariance of systems is taken up and explained in a highly complex, changeable world. This "qualifies cybernetics as an uncompromisingly non-ontological research approach and reveals a surprising proximity to the functionalist systems theory of sociology" (Luhmann 1968, p. 107). ${ }^{4}$

It is the orientation of systems theory on regulatory purposes that could be the reason for the technical application context predominating in the pioneering years and cybernetics earning a reputation of being a technical discipline. ${ }^{5}$ Because of this, the application of its principles to social phenomena has often been misunderstood as a transfer of technical principles to non-technical contexts. However, when Norbert Wiener published his fundamental work in 1948, he left no doubt that he wished to see his scientific theory, which he called "cybernetics", addressing not only technical systems but also all systems, including living and social systems (Wiener 1948) and it was therefore an interdisciplinary scientific programme that could bear fruit both in the natural sciences and the humanities and social sciences. ${ }^{6}$ Gregory Bateson took up this claim in his well-known publication "Steps to an Ecology of Mind" (1972) and can boast fruitful experience with the cybernetic principle in biology, anthropology, psychology and epistemology. Here, the family therapy approach pursued by the so-called Palo Alto School, centring on Bateson, Jackson and Watzlawick, ought to be stressed (Marc and Picard 2000). Today, management research can also boast a much tried and tested application of systems theory and cybernetic principles (Beer 1959; Beer 1981).

The transfer of cybernetic principles to societal processes has been subject to strong

\footnotetext{
${ }^{3}$ The approach of defining the identity of living organisms by way of their organisation was already anticipated by La Mettrie: "But since all the faculties of the soul depend to such a degree on the proper organisation of the brain and of the whole body, that apparantly they are but this organisation itself, it is quite obviously a machine" (De La Mettrie 1985, p. 67)

${ }^{4}$ Translated by the author

${ }^{5}$ However, there are a number of theory-immanent reasons that will be dealt with below.

${ }^{6}$ Also cf. Karl Steinbuch, who, in the fourth edition of "Automat und Mensch", which was very important for cybernetics in Germany, added the subtitle "Auf dem Weg zu einer kybernetischen Anthropologie" (towards a cybernetic anthropology) (Steinbuch 1971)
} 
criticism right from the start. Suffice it to mention the debate on Georg Klaus' "Kybernetik und Gesellschaft" in the former German Democratic Republic (GDR) (Klaus 1965; Friedrich, Schweizer, and Sens 1975). A scientific breakthrough only seems to have come in the mid-80ies, when Niklas Luhmann transferred Maturana's theory of autopoiesis to social systems ${ }^{7}$ and adopted the constructivist ideas of "second order cybernetics". However, Luhmann applies the cybernetic principles in a very unconventional manner, and partly only after considerable theoretical revisions. In the following, I would like to examine the issue of how strongly cybernetics really has influenced Luhmann's work, and to what degree it can therefore be referred to as sociocybernetic. First of all, I wish to develop criteria according to which a theory can be called cybernetic. I will subsequently reconstruct Luhmann's handling of the most important theoretical issues of cybernetics.

It can thus be stated that most authors stress the issue of regulation - and in the context of complex and dynamic systems, this always and above all implies self-regulation - as the crucial aspect that makes a system a cybernetic system. Here, however, it has to be stressed that conversely, it is only this question that brings the systemic aspect of the world into a dominant focus of research. Bearing this in mind, the following aspects can be emphasised that may be seen as characteristic of cybernetic approaches:

1. System aspect: Research interest focused on handling complexity. A systemic view is an observation attempting to trace the diversity of interaction in reality instead of analytically isolating individual causal relations and exploring them in their entire depth. Systems are defined by a certain form of distinction from their environment.

2. Processuality: Cybernetics "treats not things but ways of behaving. It does not ask 'What is a thing?' but 'What does it do?'” (Ashby 1957). It is not the nature, the properties, the materiality of objects that forms the centre of its interest but their forms of operation.

\footnotetext{
${ }^{7}$ As readers will know, Maturana himself objected to this transfer. His own concept of society is strongly characterised by the application of biological principles to social phenomena. The existing biological unity that human beings have realised via sexual cognition also ought to enable them to create a similarly shaped union in the cultural sector. This would require the creation of a common area of experience with similar preferences for all people. This cannot be realised by science but only through "the art of living". Purely biologically, the notion of the spontaneous transformation of a society as a biological entity leads to a system free of oppression which does not negate the individual is an illusion. "Such a system can only be designed as an artefact of human creativity, namely thereby that all individuals are regarded as important und that the social system which is building by their interactions becomes a non-hierarchical allopoietic system, which makes their life worthwhile" (translated by the author) (Maturana 1982, p. 312). Thus Maturana regards society as a type of organisation in the sense of a means (tool) to satisfy human needs, which tends to be a disconcerting view for a sociologist.
} 
3. Receprocity: It is not causality but the mutual influence of dynamic self-regulating systems that research focuses on. With a cybernetic approach, one has opted for the examination of the basic forms from which the internal order of a system results rather than for observing individual properties.

4. Self-referentiality: To Heinz von Foerster, this is the fundamental principle of cybernetic thought. He speaks of circularity, referring to all concepts that can be applied on themselves, processes in which a state ultimately reproduces itself (Foerster 1993a, p. 73). Luhmann adopts this concept under the headword "self-referentiality".

5. Information aspect: System processes, especially the relation between the system and the environment, are understood as "informational processes" in which contingencies exist and selection occurs rather than as necessities in the sense of a strict causality. Information is often referred to as a function of the organisation of systems. Some natural scientists regard information as a "third factor" next to matter and consciousness (Weizsäcker 1974) or matter and energy (Stonier 1990).

6. Regulatory aspect: The purposeful influencing of social phenomena always amounts to an attempt to intervene in highly complex systems with self-organising (dissipative) structures. These systems respond to attempts to regulate them coming from their environment only on the basis of their internal structure. Thus regulation has to handle the phenomenon of the determinedness of systems' structures.

\section{Questions about cybernetics}

Luhmann sees the nucleus of cybernetic thought in the notion that a system whose operations are oriented on the fulfilment of certain purposes will orient its behaviour on a constant feedback from the environment and can therefore cope with a high, unknown level of complexity. In this manner, the system can maintain a constant level of permanent impact in spite of different and constantly changing environmental impacts. The means applied by the system may be dosed differently, and possible changes in the environment may be compensated for by self-modification. "“It has no need to anticipate these changes in the environment or integrate them in its planning ex ante. It experiences them ex post (although if possible immediately) via the feed back of the result of its own effectiveness and will subsequently accordingly modify its operations."' (Luhmann 1968, p. 108) ${ }^{8}$ Re-

\footnotetext{
${ }^{8}$ Translated by the author
} 
garding the environment issue, Luhmann later on refers to this ability to resort to selective but swift responses as "resonance capacity" (Luhmann 1989, pp. 15).

Luhmann processes cybernetics - more implicitly than explicitly - in the context of the critical treatment of some basic problems of systems theory. They are first of all the relation between stability and disturbance and their treatment in the cybernetic model of equilibrium, secondly the system/environment relation and the relation between entropy and negentropy in the context of the theory of open systems and thirdly the issue of regulating complex dynamic systems. A fourth aspect of cybernetics that Luhmann is critical of is how it handles the concept of purpose. However, this controversy will not be dealt with in further detail here because Luhman later on revised his position in this respect, following his adopting Maturana's concept of autopoeisis. ${ }^{9}$

\subsection{Stability and disturbance}

Unlike the classic cybernetic descriptions, which identify the stability of systems with their equilibrium, Luhmann doubts whether maintaining a system in a state of stability (in the sense of a function of equilibrium) can be a value in its own right. He points to the debates that already arose longer ago in this respect and questions whether an equilibrium can be referred to as a stable condition in the first place. This is an issue that suggests itself particularly from an empirical angle, if the focus is not only on mathematical functions but on real economic or organisational systems distinguished by a high degree of dynamics. Taking up the issue of why those institutions that are supposed to guarantee the equilibrium of a system ought to endeavour to keep the system in equilibrium, he suggests that it might make sense to assume precisely the opposite, i.e. to regard nonequilibrium as a condition of stability (Luhmann 2002, p. 44). This notion already played an important role in Luhmann's debate with the structural functionalist system theory presented by Talcott Parsons and ultimately resulted in a significant correction of Parsons' theory. Luhmann no longer determines the character of a social system as a unit with the aid of certain value and structure patterns, the maintenance of which guarantees the system's stability, as formulated by Parsons, but solely with the recursive, mutually referential social actions (= communication). Whenever there is a succession of communicative actions, a social system will evolve that delimits itself from an environment. Thus, with Luhmann, disturbance is not an expression of a crisis threatening a system's stability that could either

\footnotetext{
${ }^{9}$ Luhmann accuses cybernetics of radically simplifying the notion of purpose, which results in its not being suitable for a theory of social systems (Luhmann, 1968, pp. 107-113).
} 
be overcome by restoring the old state or via the establishment of a new equilibrium. ${ }^{10}$ Rather, to Luhmann, disturbance represent irritations or stimuli for a system that can trigger resonance in it. What resonance is created, i.e. to what concrete modes of behaviour the system is necessitated, depends first on the options the system's existing structure provides and second on all other factors "irritating" the system. Here, Luhmann's reference to Maturana's concept of "perturbation" can be very clearly recognised.

Luhmann rejects the assumption that social systems necessarily depend on specific performances that cannot be substituted. Social systems do not cease to exist if certain system performances fail. In certain conditions, the latter can be replaced with alternative system performances.

A social system can also enable its further existence by changing its needs or modifying its structures, given changed conditions, without it being possible to clearly determine from when on such changes constitute a new system that is no longer identical with the old one (Luhmann 1972, p. 33). While the replacement of an organisation's leadership hierarchy with a multitude of small, self-organised units with self-determined external relations of their own will change mutual expectations, it need not necessarily jeopardise the organisation's unity. This is why, in sociological analysis, Luhmann no longer focuses on the issue of what concrete causal relations ensure a system's existence but on what system performances can be rendered by what functions and what equivalences exist to this end. It is no longer functional causality that bears relevance but functional equivalence (Luhmann 1995, p. 52), with the scope of options for equivalent operations being defined by the system's structure.

With these theoretical assumptions, the concept of disturbance attains a modified meaning. It shifts from an event occurring in a system's environment to a system-internal event. In this sense, disturbance is nothing else but the initiation of a process that can be handled operatively in the system (Luhmann, 2002, p. 127) and through which resonance to events in the environment is generated in the system. And since - as we have seen - the operative area of options in which the system can act is defined by a system's structure, any interference implies the system's practical reverting to its own internal structure for the purpose of selecting a suitable action. Luhmann calls such reverting self-referentiality. Again, Maturana's influence, already mentioned above, can be clearly recognised.

It can thus be shown that Luhmann seeks to separate the concept of distrubance from its traditional bondage with the cybernetic model of equilibrium and use it to describe processes that have traditionally been more associated with the concept of information

\footnotetext{
${ }^{10}$ This is why Luhmann replaces Parsons' term of structural-functional system theory with the term of functional-structural system theory.
} 
in cybernetics (Luhmann, 2002, p. 127). However, this in turn also implies - as will be shown in Section 3 - a semantic shift in the concept of information (Luhmann, 2002, p. 127).

\subsection{System/environment relation}

Reformulating the cybernetic understanding of stability is associated with a reinterpretation of the basic theoretical understanding of the relationship between the system and the environment, which had however already been hinted at in the cybernetic and systems theory discussion prior to Luhmann, especially in Bertalanffy's work (Bertalanffy, 1968).

Initially based on physical observations, the formulations of systems theory related to systems in their kinetic and thermodynamic properties. Following the laws of thermodynamics, these systems tend to assume entropy, i.e. a state in which all distinctions have been eliminated, an unstructured state in which no distinctions can be made and in which all possible links are equally probable. This state is also called highly complex or chaotic.

However, thermodynamics sets out from the assumption that the systems dealt with are closed, that nothing can penetrate them from outside and nothing can escape them. While such a model can be imagined from the angle of physics for the world as a whole, it does not fit the conditions within the world. This is why Bertalanffy had already rejected the notion of closed systems for biological systems and instead advocated a theory of open systems (Bertalanffy, 1968).

In the context of such a theory, consideration had to be given to the type of exchange relations between a system and its environment, which, for example, was put into concrete terms in biology as the issue of energy supply, and for (social or psychological) systems as the issue of information processing. ${ }^{11}$ It was asked whether there are specific conditions in a system's environment, such as other systems, that are relevant to the system's existence and (owing to a certain input) may cause it to display a certain behaviour (i.e. a certain output).

Luhmann describes two different answers that were initially given to this question by early systems theory (Luhmann, 2002, pp. 47). One of them supposes a transformation function via which a structurally determined relation between input and output is realised: A certain output can clearly be traced back to a certain input. Interest taken in this model by engineering science can be explained by its supposing technical repetition. The same input to which the same function is applied will in turn yield the same output. For ex-

\footnotetext{
${ }^{11}$ The partly confusing relation between information and entropy will be discussed in more detail in Section 3.
} 
ample, this notion has been put into concrete terms in microeconomics by assuming that certain environmental constellations would allow conclusions to be drawn regarding the establishment of an adequate organisational structure of businesses, a "one best way". Similar assumptions were made in psychology and in political science. But difficulties occurred precisely in the attempt to apply this ideal mathematical model to reality that then resulted in the development of a different model of the system-environment relation.

This second model is oriented on the notion of the black box: owing to its complexity, a system's interior cannot be recognised. However, from observations of regularities in the external relations that a system has, one can deduce that there must be some mechanism that can provide an explanation for the reliability of a system, for its rationality, for predictability of its outputs given certain inputs (Luhmann, 2002, p. 49). Although this black box model dissolves the notion of a rigid, mechanical or mathematical coupling of input and output, it is still subject to certain structural basic assumptions with which some important questions cannot be answered: What arrangements of structure and operation see to it that certain inputs correlate with certain outputs? What are the acts of selection relating to this based upon?

Luhmann finds the answers to these questions in the work of the group around Heinz von Foerster, Humberto Maturana, Francisco Varela and others, in which the forms of exchange between the system and the environment are not - as is the case with the earlier approaches of systems theory criticised above - determined by the environment but by the system itself. What is crucial to this theoretical reconstruction is the distinction between "trivial" and "non-trivial systems" (by Foerster) or "allopoietic" and "autopoietic systems" (Maturana), which I will deal with in closer detail in Section 3. Autopoietic and non-trivial systems perform their operations self-referentially by orienting them on their concrete internal structures and conditions. This is why Maturana characterises these systems as "structure or condition-determined", and v. Foerster, following Löfgren, as "autologic". Thus a renewed reorientation is performed in systems theory, this time towards "unity". Here, however, the object is not that of returning to the beginnings of theoretical development. As will be demonstrated more closely below, this is a theoretical change that produces a new - one might be tempted to say: dialectic - relation between closedness and openness. Here, the emphasis is not on general energetic closedness as was assumed in the original physical models but on operative recursivity, self-referentiality and circularity. It is only this operative closure, Maturana already stresses, that enables the openness of systems, i.e. their exchange with the environment.

With this reconstruction of systems theory, "a differentiated system is no longer simply composed of a certain number of parts and the relations among them; rather, it is 
composed of a relatively large number of operationally employable system/environment differences, which each, along different cutting lines, reconstruct the whole system as the unity of subsystem and environment." (Luhmann, 1995, p. 7). The difference between system and environment is the precondition for the identity of systems (243). "Everything that happens belongs to system (or to many systems) and always at the same time to the environment of other systems (Luhmann, 1995, p. 243). Any change in a system simultaneously implies changes in the environments of other systems.

One can see that "Systems are oriented by their environment not just occasionally and adaptively, but structurally, and cannot exist without an environment. (...) difference is the functional premise of self-referential operations. In this sense, boundary maintenance is system maintenance." (Luhmann, 1995, pp. 16). "The environment receives its unity through the system and only in relation to the system. (...) It is different for every system, because every system excludes only itself from its environment" (p. 17). Adapting systems theory to the system/environment difference as the theoretical guiding principle torpedoes the old thematic of relations between domination and oppression (p. 17). This tradition (already started by Aristotle) had set out from a distinction between the whole and its parts. Autonomy (i.e. activities on the basis of insights into the living together of people) was only possible by recognising the whole (p. 5). ${ }^{12}$

\subsection{Regulation and feedback}

The third thread of theory - characterised by cybernetics - that Luhmann deals with is the issue of regulation. In a cybernetic context, Luhmann maintains, regulation does not mean that one can determine the future state of a system. This is neither possible in the general context, in the essence, if one will say it in "old-european terms" (Luhmann, 2002, p. 54), nor in all concrete details. All that is possible is not to let specific differences get too large or to reduce them. Deviations relate, for example, to a certain temperature or a target. Here too, however, the difference cannot be fully controlled by the system. It can only experience an alteration via an external impact that can then in turn be corrected by the system (negative or positive feedback). ${ }^{13}$

\footnotetext{
${ }^{12}$ In contrast, Luhmann defines autonomy - with reference to Varela - as self-referential closure, as a generation of its unity through the system's own operations (Luhmann, 1990, p. 289).

${ }^{13}$ However, Luhmann does ask whether society disposes of something like natural braking mechanisms or whether the reinforcement of deviation, once performed, can only be stopped by crisis or even disastrous developments.
} 


\section{Luhmann's systems theory as socio-cybernetics}

Setting out from Luhmanns' above-mentioned dispute with systems theory and cybernetics, from which he develops his theory, I would now like to again take up some of the fundamental characteristics of a cybernetic approach already referred to in Section 1 and examine how Niklas Luhmann applies these basic cybernetic principles in his systems theory. Here, the central aspect will be to show what Luhmann understands by a cybernetic system, and the classic cybernetic question is newly formulated: If system is no longer regarded as an object but as a difference in which the system is located on one side and the environment on the other, how is this difference created, maintained, reproduced and subjected to evolutionary change?

\subsection{The concept of system}

In philosophical tradition, "system" often refers to what has been composed, as opposed to the elementary, what has not been composed. In this manner, a certain fundamental distinction is turned into the starting point of scientific observation: the distinction between the whole and its parts. For example, Hegel views "das Wahre nur als System wirklich" (Hegel 1970, p. 28). The individual unit has to remain incomprehensible as long as it is not observed in its context with other elements. In philosophy, this issue has above led to heated debates regarding the explanation of life. Since Aristotle, the identity of living organisms has been defined by their performing certain functions (to fulfil purposes) in the whole of their interaction. Without considering this wholeness, they would lose their functions and would be something different from what they are as organs: they would be reduced to their existence as mere parts. Kant sees the parts and the whole in a mutual functional relationship that he refers to as the "inner purposiveness of nature". The parts are only possible thanks to their relationship with the whole, and they combine to form the whole in a manner in which the parts and the whole act mutually as the cause and the effect of one another. "(...) a thing exists as a natural end if it is cause and effect of itself (although in a twofold sense)" (Kant 2000, § 64, p. 243)

A closer look reveals that the relation between the whole and its parts is also considered in a double sense in philosophical tradition: This can be shown very well with Kant, because on the one hand, he stresses the totality of all parts, but on the other the unity of this totality, which, as the reader will know, is more than, or at least different from, the sum of the parts. Nowadays, this being different of the whole compared to the sum of the parts is referred to by the term emergence. Systems cause properties that are no longer 
explainable with the properties of their elements.

In using the system concept, Luhmann takes up this ambiguity but simultaneously performs a semantic turn of the system by linking it up with state of the art in sociology and biology. Having initially been fascinated by Parsons' notion of describing social acts as "systems". ${ }^{14}$ in theoretically elaborating the concept of the system, he encounters the research work of cybernetics and general systems theory. The works of Ludwig von Bertalanffy, Heinz von Foerster, Humberto Maturana and Francisco Varela have a particularly strong impact on his further activities and result in a theoretical reconstruction in which two important modifications are performed in contrast with philosophical tradition: The first modification is to abandon, to a large degree, the concept of purpose. The second modification is that the system no longer gains its identity via the relations of the parts to the whole but via its relation to its environment.

Maturana and Varela maintain the view that "ends" and "functions" no longer bear any explanatory value (Maturana and Varela 1982, p. 191). Nothing occurs in the evolutionary history of living systems because it is necessary. Once certain phenomena have occurred, they are there, and then their existence is unavoidable. "The sole necessary condition in any given area is those to be a unity, i.e. separable from the environment and therefore distinguishable from other unities." (p. 200) ${ }^{15}$. Maturana and Varela hold that the question of life cannot be answered by seeking the necessary properties of living organisms but by identifying their organisational principles.

With the aid of the paradigm of the system/environment difference, ${ }^{16}$ emergent systems are described as a constant repetition of this difference at various levels. Complex systems then no longer simply consist of a certain number of parts and relations between them but of a more or less large number of system/environment differences that reconstruct the overall system as a unity of sub-systems and environment at various lines of intersection (Luhmann, 1995, p. 7). Here, the issue is not that of a network of fixed elements or substances but of a network of operations belonging to one another that can be delimited from operations not belonging to them. The equality of the operations constitutes the system's identity. Thus, in analogy to the definition, it is determined that systems can only operate within their own system boundaries. They have no opportunity to intervene in other systems, dock onto their environment or modify this coupling (Luhmann

\footnotetext{
${ }^{14}$ Parsons no longer regards the unit act as the expression of an acting subject, an actor, but as an emergent property, reality, and thus as a result of the interaction of various factors of which the actor is only one alongside the existence of societal structures and the means and purposes at work in them.

${ }^{15}$ Translated by the author from the German edition

${ }^{16}$ Luhmann refers to this as the central paradigm of new systems theory (Luhmann, 1995, p. 176)
} 
1990, pp. 29). Their operations are performed self-referentially, i.e. they are oriented on the state of their own (and only their own) system, its structural conditions, and criteria of relevance. System thus becomes a relational term. Maturana calls such systems operatively closed and structurally determined, while v. Foerster speaks of autological and non-trivial machines (Foerster 1993b).

Operative closure does not mean isolation from the environment. Without doubt, an energy or materiality continuum must be presupposed for which the system boundaries do not represent any problems. What counts is the type of process (operations) in which interaction between different systems or sub-systems occurs. What is meant is the notion that effect relations can no longer be grasped as "input-output" processes, as was the case in early cybernetics, but as autonomous, self-regulatory processes. While environmental influence triggers a system's responses, it does not determine them! How the system (or the sub-system) changes primarily depends on the properties, the state of the system, its respective structure and the system's internal references. ${ }^{17}$ The system itself determines - via the sequence of its own changes in its state - what can, at all, act as an "input" at a given moment and in a given situation. Thus the system constructs its reactions to environmental impacts itself.

So the assumption of a centre of gravity that organises the sub-systems for itself (i.e. in accordance with its objectives) - as Kant maintained - has been abandoned. It has been replaced with the multitude of system/environment relations leading to a spontaneous order, to the self-organisation of the system as a whole. Maturana refers to this kind of organisation in the context of biological research as "autopoietic" because the interaction of all components of a cell makes it possible to reproduce itself as an autonomous unit and assures its survival (Maturana and Varela, 1985).

Luhmann separates the "autopoietic principle" from its narrow biological context of emergence and generalises it. Living systems, conscious systems and social systems are examples of different systems operating in complete separation. No doubt life is the precondition for consciousness and communication, however not in the sense of a causal relation but as simultaneity, as a mutual relationship that emerged in a co-evolutionary process. Maturana calls this structural coupling. Systems are structurally coupled if they are mutually conditional (e.g. consciousness for communication, communication for consciousness) but each system operates according to entirely different organisational principles, for example psychological systems through thinking, social systems through communication, organic systems through chemical metabolic processes. The elements of

\footnotetext{
${ }^{17}$ Maturana speaks of "structural determination", and Luhmann of "self-referentiality" or "selfselectivity".
} 
the system of consciousness are thoughts. Thoughts can only link up with thoughts. According to Luhmann, the elements of social systems are communication. Communication can only link up with communication. ${ }^{18}$ While consciousness is involved in communication, this is not so in the sense that it communicates itself.

From the angle of this theory, humans cannot be systems because they consist of several systems operating separately, such as the organic system, the immune system, the neurophysiological system and the psychological system. All of them operate completely without overlaps. They relate to one another via structural coupling. Thus, from the angle of systems theory, society is not a collection of human individuals but communication.

Operative closure also exists between equal systems. For example, there is no direct link between certain organic systems that are delimited from one another or among several psychological systems. Different social systems, e.g. the economic system or the social system, perform self-referentially closed communication that does not allow them to operate across systems. Neither is it possible for a certain system of consciousness to directly refer to another consciousness with the aid of its operations (= thoughts), not via communication, either. There is no transfer of meaning from one consciousness to another. ${ }^{19}$

That it is nevertheless possible to create a relation is due to the structural linkage of psychological systems with social systems. Via the network of their elements (communication), social systems provide a basis for the interpenetration of the different systems. One system of consciousness can influence another via communication, can stimulate it, ${ }^{20}$ but cannot cause it to display a definite behaviour.

The concept of system described gives rise to two further questions: first, what specific type of operation performs the reproduction of the system/environment difference in a given case and, second, how can a system recognise what operations belong to a system and what operations do not? The first question points to the functional differentiation of modern society, while the second one points to the problem of observation in the sense of a simultaneously progressing operation of distinguishing and naming. Both aspects will be dealt with in further detail below.

\footnotetext{
${ }^{18}$ This results from the constitutive rule of sociology that the social can only be explained by the social (Durkheim 1965), and not by biological, chemical or psychological aspects.

${ }^{19}$ Thus the self-referential closure of systems is represented in two respects. On the one hand, there are different types of system that are composed of such different system elements and operations that they rule out any links and on the other, equal types of system that use equal types of operation but are nevertheless separated by system boundaries. The issue here is that of the internal system/environment differentiation of systems.

${ }^{20}$ Maturana speaks of perturbations, and Luhmann of irritations.
} 


\subsection{Self-referentiality}

A system's self-referentiality results from the fundamental and already described premises of systems theory, defining the existence of a system purely by the recursive operations referring to each other and not via an identification and classification, whatever form this may assume, of a recognising subject. With the term of self-referentiality, Luhmann is following up on one of the most important cybernetic concepts, that of the self-referentiality of systems. That he does not use the classic term of "feedback" follows from the already described revision of the system concept and the redefinition of the system/environment relation. His adopting the autopoiesis concept resulted in one having to recognise that systems can have no immediate relationship with their external world. Everything that happens in the world can only be processed by the system by relating to the internal conditions and to its own range of operations.

Luhmann repeatedly points out that the self-referential closure of systems ${ }^{21}$ not only rules out their openness but, on the contrary, is the precise condition for systems being able to establish contact with a complex and distanced environment. This clarification bears both a delimitation and, simultaneously, the connectivity of Luhmann's systems theory to classic cybernetics.

A delimitation is performed in that the assumption is abandoned that one can always transform causes into effects (inputs into outputs) in the same manner and hence cause the system to respond in a predictable manner provided that one knows the transformation function. Since the question of how a system responds to the inputs in its environment always depends on the condition into which the system has brought itself (via its own operations), the relation between the external events in a system's environment and the internal structures has to be explored more closely.

The historical situation that a system is in is due not only to the fact that the environment has changed but also to its having changed itself (Luhmann, 1990, p. 277). In this context, Heinz von Foerster speaks of "non-trivial systems", i.e. systems that are synthetically deterministic but analytically indeterminable and unpredictable in terms of their behaviour owing to their dependence on history (von Foerster 1993, p. 252).

Luhmann's connectivity to cybernetics can be recognised by his regarding the possibilities to relate to the external world in a specific selective performance that he refers to as information. ${ }^{22}$ Without this selection, the environment would exist for the system in

\footnotetext{
${ }^{21}$ It also bears a system's autonomy (Luhmann, 1990, p. 289).

${ }^{22}$ Thus Luhmann also takes Ashby's claim into account that the self-organisation of a system that does not relate to the environment is impossible (cf. Luhmann, 1990, p. 276).
} 
a completely entropic state and without any discontinuities, and no observation and no relation to the environment could develop (Luhmann, 1990, p. 303).

It can first of all be stated that Luhmann follows the cybernetic insights on selfreferentiality and circularity in the modes of operation of systems. ${ }^{23}$ However, the systems have to be in a position to distinguish what belongs to the system from what does not. And since, as already stressed, systems constitute themselves solely via their operations, this implies distinguishing their own operations from those in the environment. In answering the question how systems can be in a position to do this, Luhmann encounters familiar problems of the philosophical debate on the subject/object relation or the dualism of intellect and body, which, however, cannot be dealt with in detail here. Rather, Luhmann's definition will have to suffice in this context: "One can call a system self-referential if it itself constitutes the elements that compose it as functional unities and runs reference to this self-constitution through all the relations among these elements (...)" (Luhmann, 1995 , p. 33). ${ }^{24}$

\subsection{Information}

In Chapter 2, it was pointed out that Luhmann separates the concept of disturbance from the classic cybernetic model of equilibrium and uses it to describe processes that are usually seen in the context of information in cybernetics. To this end, he has to perform a semantic shift of the information concept (Luhmann, 2002, p. 127) that will now be looked at more closely. Clarifying this modification is of considerable importance in assessing the significance of Luhmann's work for cybernetics because, as the reader will know, in Luhmann's theory of social systems, it is communication, and not information, that is presented as the basal category. This gives rise to the question to what degree Luhmann's theory of social systems really can be seen as part of a continuous line, together with cybernetics, in spite of its several theoretical references, or whether it does not instead represent a break of this tradition. ${ }^{25}$

\footnotetext{
${ }^{23}$ In this respect, he assumes a critical distance from "so-called radical constructivism", which he accuses of "not yet having done its homework properly" since it still sticks to the traditional European guiding distinction between the subject and the object (Luhmann, 1990, p. 521).

${ }^{24}$ Here, it can only be pointed out that regarding the self-description of a system, Luhmann distinguishes between different levels of reflection each of which is characterised by a special form of self-observation. However, Luhmann is sceptical about a possible rationality with respect to society as a whole resulting from this. He regards it as highly improbable, since to him no representation of society that would be free of competition is conceivable that could represent the whole (Luhmann, 1995, pp. 443 and 1997, pp. 866)

${ }^{25}$ Despite the clear dominance of the communication concept, there are scattered indications of continuity in Luhmann's work: "The method of functional analysis that we will assume throughout is based on the
} 
No doubt information is one of the key terms of cybernetics, even though, just like other concepts, it has never been given a standard definition. And it is certainly no exaggeration to claim that the inconsistent use of this key term may have contributed to the hopes originally associated with cybernetics of overcoming the division between the natural sciences and the humanities have not been fulfilled so far. Whereas on the one hand, information has been referred to as a phenomenon of being (for example in the context of genetic information $)^{26}$, on the other, information has been regarded as an event generating meaning in communicative or action contexts. ${ }^{27}$

At no point in his work does Luhmann treat the various concepts of information presented by cybernetics in detail. Information is usually only dealt with in connection with the discussion of his communication concept. However, it does become clear that Luhmann refers to various cybernetic authors and addresses various issues there. For example, regarding Norbert Wiener and Heinz von Foerster, he adopts the aspect of structure and order formation by information ${ }^{28}$, thus counter-positioning himself to Shannon, who, as the reader will know, has conversely referred to information as an expression of entropy and hence as a measure of disorder. However, at the same time, he relates positively to Shannon by sharing his view of information as selection and not as a substance of whatever nature. What can clearly be recognised is Ashby's influence on formulating the distinction between utterance and information, which plays a central role in Luhmann's concept of communication. This distinction and the event character of information that was formulated by Bateson (and again contradicted Shannon) are the theoretical building blocks with which Luhmann opposes the transmission metaphor in communications science literature.

"The metaphor of transmission is unusable because it implies too much ontology. It suggests that the sender gives up something that the receiver then

concept of information. This method serves to obtain information. (Whether this also pertains to 'explanation' depends on the account of the concept that one gives). It regulates and specifies the conditions under which differences make a difference." (Luhmann 1995, p. 52). Also cf. Luhmann, 2002, pp. 127.

${ }^{26}$ Cf. here (Ebeling, Freund, and Schweitzer 1998; Stonier 1990)

${ }^{27} \mathrm{Cf}$. here Bateson: “The technical term 'information' may be succinctly defined as any difference which makes a difference in some later event. This definition is fundamental for all analysis of cybernetic systems and organization" (1972, p. 381). Also cf. Weizsäcker, who puts more emphasis on the issue of semantics: "Information is only what can be understood" (Weizsäcker, 1974, p. 351).

28“Therefore information is an event that constrains entropy, without thereby pinning down the system" (Luhmann, 1995, p. 68). Also (cf. Wiener 1951, pp. 82). Also cf. H. von Foerster, who has formulated the principle of "Order from Noise" (von Foerster, 1993). 
acquires. This is already incorrect because the sender does not give up anything in the sense of losing it. The entire metaphor of possessing, having, giving, and receiving, the entire 'thing metaphoric' is unsuitable for understanding communication.” (Luhmann, 1995, p. 139)

Systems - and in particular systems processing meaning - have no other option but to reduce the descent in complexity between the diversity of events in the environment and their own processing capacity, which is connected to their operative closure and cannot be avoided, via specific selective performance. They have to minimise the multitude of options to respond to random environmental stimuli in order to remain able to act.

The problem that both Luhmann and Shannon are confronted with is that of filtering the relevant signals out of a multitude of options (signals on hand). ${ }^{29}$ Shannon concentrated on the issue of how signals could be transmitted in spite of inevitable interference in the course of the message transmission process out of which information emerges. Any interference can be treated as a message or a signal in its own right. And initially, no distinction can be made between information and disturbance because one cannot yet determine which of the signals are unexpected or undesirable (i.e. which ones interfere) and which ones are desired. In the case of Shannon, related to the technical problem of communication, this is the task of communications technology. But it can no doubt be generalised and referred to as the task of any information-processing system.

To Shannon, signals generally emerge from noise. There is no transmission of "faultfree", signals that emerge clearly comprehensible. Noise is the precondition for information. ${ }^{30}$ Messages will only acquire their information content against the background of the other alternatives that may be conceivable but are not selected in the specific situation. The more extensive the latter are, and the more often a selection has to be performed, the higher a message's content, according to Shannon.

Thus information relates "not so much to what you do say, as to what you could say. That is, information is a measure of one's freedom of choice when one selects a message" (Weaver 1963, p. 100). In other words, the more alternatives it rules out, the higher information will be. Shannon ascribes the highest value of information content

\footnotetext{
${ }^{29}$ With the issue of what criteria are used, what a system deems relevant and what it does not, remaining unsettled.

${ }^{30}$ Systems have no other option but to make use of noise to acquire or construct information. Information will not be sought without the uncertainty caused by the noise. This also applies in the case of Bateson: "All that is not information, not redundancy, not form and not restraints - is noise, the only possible source of new patterns" (Bateson 1972, p. 410).
} 
to the message with the lowest probability. ${ }^{31}$ Conversely, if a message is expected with certainty, or if its arrival follows a necessity, then its informational value will be nil. ${ }^{32}$ Thus to Shannon, information is the expression of the probability or improbability of the occurrence of events if a limitless and dynamic supply of signs are used, measured in "binary digits" (bits). This can also be regarded as a system's measure of entropy (Shannon 1963, pp. 18; Weaver, 1963, pp. 103)

Luhmann no longer follows Shannon at this point. What he accepts is the aspect that brings the novel character of information to the fore (Luhmann, 1995, p. 67), and that noise raises information, without, however, laying claim to wishing to measure the degree of information. In particular, he does not follow Shannon's proposition on entropy. No doubt it is particularly the unexpected, the surprising (and also the undesirable) that rouses our attention, which is also what makes it informative. And in this sense, any disturbance enriches communication (in the sense of generating information). But while Shannon refers to signal processing that is performed in the external world of an observer and information-generating selection therefore increases entropy in the external world, Luhmann shifts this to the internal world of a system observing the environment. And it is at this point that his reformulation of the concept of information sets in: Information occurs whenever a selective event (of an external or internal kind) works selectively within the system, namely, can select the system's states " (Luhmann, 1995, p. 40). Here, Luhmann directly follows Bateson: "A 'bit' of information is definable as a difference which makes a difference. Such a difference, as it travels and undergoes successive transformation in a circuit, is an elementary idea." (Bateson 1972, p. 315) ${ }^{33}$. This means that information only acquires its character as information when it triggers an internal modification of conditions in a system.

Such an internal modification of conditions presupposes existing structures that somehow pre-arrange the options for action. What counts in a given situation is how a system makes use of its internal structures, what options for action it updates and mobilises and which ones it does not resort to. Information only occurs temporarily as an event. However, it is not lost, for it leaves behind a structural effect via the modification of the

\footnotetext{
31 "It is generally true that when there is noise, the received signal exhibits greater information - or better, the received signal is selected out of a more varied set than is the transmitted signal." (Weaver, 1963, p. 109)

${ }^{32}$ Similarly, Luhmann writes: “(...) information that is repeated is no longer information " (Luhmann, 1995, p. 67).

33"In fact, what we mean by information - is a difference which makes a difference, and it is able to make a difference because the neural pathways along which it travels and is continually transformed are themselves provided with energy." (Bateson, 1972, p. 453)
} 
system's condition. Against this background, Luhmann can now state: "Information presupposes structure, yet is not itself a structure, but rather an event that actualizes the use of structures" (Luhmann, 1995, p. 67).

So we can formulate the chief differences between the theories of Shannon and Luhmann as follows: Shannon defines information as a selection from signals that exist in the external world. This means that information acts as an input into the system selecting it. Since Shannon only relates to the technical problem of how signs can be transmitted as accurately as possible, he does not make any statements on the semantic or pragmatic aspects. However, one can assume that he sets out from messages which, once they have been selected by the recipient, are the same both to the transmitter and the recipient, and that they mean the same to both. This assumption of a transmission of information has persistently been criticised from a humanities and social science angle, and today, especially against the background of a second-order cybernetics, it is no longer tenable in the natural sciences either. Even if, seen empirically, an item of information does have the same meaning for the transmitter and the recipient, this is not guaranteed by the content quality of the information but is only constructed in the course of a process of communication (cf. Luhmann, 1995, pp. 139).

To Luhmann, the environment does not contain any information at all. There are no circumstances that can simply be registered or ignored. There are no objects that could be viewed from various angles and the quantities and properties of which one could determine. Information is permanently produced within the system itself, in the course of communication. As opposed to Shannon, Luhmann focuses more strongly on the internal conditions of a system. He is above all concerned with the issue of how the selfreferentially operating system relates to its environment via information. This is where the different application contexts of the two theories also become apparent. ${ }^{34}$ Having initially generalised a purely technical understanding of Shannon's concept of information with regard to the aspect of selection, Luhmann now limits it to systems that are capable of orienting themselves on differences (e.g. on the difference between external and internal conditions), in other words on systems that are tied to a self-referential mode of operating (Luhmann, 1995, p.40) or, as H.v. Foerster puts it, to "non-trivial systems".

\footnotetext{
${ }^{34}$ Regarding Shannon's concept of mathematical information theory, Luhmann leaves no doubt about its limited range of application in social sciences, which above all results from technical systems and systems processing meanings operating according to entirely different patterns. "The concept of information presented here serves only for technical calculations and leaves meaning references completely out of consideration, but this does not imply that selectivity is not important in meaning contextes" (Luhmann, 1995, p. 529, note 4).
} 
But how does this communicative constitution of information happen in social systems? Luhmann persistently clarifies that he is interested first in a non-intentional and, second, in a sociological concept of communication that differs significantly from a psychological view (also cf. Fuchs 1993, pp. 25). This means that his understanding of communication is not oriented on a speaker's or transmitter's intentions or on whether such intentions (which no doubt exist in communication) are "correctly" understood by the listener or the recipient in the sense of the speaker's original intention. In his event-oriented concept of communication, there can be no "misunderstandings", no faults and no mistakes. He wants to see how communication takes place, and how information emerges in this context. To Luhmann, understanding is an empirical event that does not yield information on what is right or wrong but solely about the communicative links. In what direction is communication moving? What answer is given to what question? Understanding merely informs about how information and utterance are distinguished from one another in a given situation. This distinction is fundamental to Luhmann's concept of communication. ${ }^{35}$

\subsection{Regulation and Control}

It has already been pointed out in Chapter 2.3. that to Luhmann, any regulation first of all can be nothing but a self-regulation of the system, and that neither the environment (or a system located in it) nor the system itself can assume complete control. It is probably in the issue of control that Luhmann and classic cybernetics are furthest apart. Regarding this question, however, Luhmann largely subscribes to the autological concept of Löfgren and H.v. Foerster, so that it is safe to refer to his concept as cybernetic, even if the specialities of second-order cybernetics have to be stressed in this context.

Heinz von Foerster distinguishes between the control behaviour of trivial and nontrivial machines. Trivial machines have evolved from a specification of the individual system elements and their mutual interaction and correspondingly respond to attempts to control them. Given a clear input, they will produce a predictable output (e.g. steering a car). In contrast, non-trivial machines have evolved through spontaneous emergent structural developments and do not respond in the sense of a clear input/output relation. They modify their behaviour solely through internal modifications of their condition. Thus in

\footnotetext{
${ }^{35}$ Luhmann defines communication as the unity of a three-level selection of information, notifying and understanding. Here, understanding assumes a special role in that it distinguishes information from notifying. The details of this construction cannot be explained more closely in the context of this essay. An elaborate account of them is given in Luhmann 1995, pp. 140.
} 
attempting to control them, one has to rely on creating such internal modifications of conditions and thus cause the system to behave in the desired direction. ${ }^{36}$

The paradigm shift caused by second-order cybernetics results in the question of possibilities to steer social systems assuming more urgency. What is of key significance here is the approach to no longer view complex and differentiated systems as a relation of the whole to its parts or of the superordinated to the subordinated, but as a relation between the system and the environment. Thus controlling a system can no longer primarily address hierarchical relations but has to take heterarchy and the diversity of operatively used system/environment differences into account.

Just how radical the control theory change introduced by second-order cybernetics really is can be demonstrated by a brief comparison with traditional approaches that also stress the principle of self-organisation. As the most prominent example, I would like to refer here to Kant's theory of the self-organisation of life. Kant's concept of selforganisation ${ }^{37}$ can be summed up as follows: The parts are only possible thanks to their relation to the whole, and they link up as a whole in a manner that parts and whole are mutually the cause and effect, purpose and means, of one another. Using a clockwork as an example, Kant describes just how much this view differs from a mechanical concept.

"In a watch one part is the instrument for the motion of another, but one wheel is not the efficient cause for the production of the other: one part is certainly present for the sake of the other but not because of it. Hence the producing cause of the watch and its form is not contained in the nature (of this matter), but outside of it, in a being that can act in accordance with an idea of a whole that is possible through its causality." (Kant 2000, §65, p. 246)

Whereas a machine merely has a force that can set things in motion, organised organisms possess a formative force, "and indeed one that it communicates to the matter, which

\footnotetext{
${ }^{36}$ With these modifications, of course, not being predictable in principle either. Unlike trivial machines, which v. Foerster characterises as 1 . synthetically determined, 2 . analytically determinable, 3 . independent of the past and 4. predictable in their behaviour, non-trivial machines are 1. synthetically determined, 2. analytically determinable, 3. dependent on the past and 4. unpredictable in their behaviour (Foerster 1993b, pp. 244).

${ }^{37}$ As far as I know, Kant was the first to use the term "self-organisation": "One says far too little about nature and its capacity in organized products if one calls this an analogue of art: for in that case one conceives of the artist (a rational being) outside of it. Rather, it organizes itself, and in every species of its organized products, of course in accordance with some example in the whole, but also with appropriate deviations, which are required in the circumstances for self-preservation. Perhaps one comes closer to this inscrutable property if one calls it an analogue of life." (Kant 2000, § 65, pp. 246)
} 
does not have it (it organizes the latter): thus it has a self-propagating formative power, which cannot be explained through the capacity for movement alone (that is, mechanism)" (Kant 2000, $\S 65$, p. 246). ${ }^{38}$ Thus to Kant, life, unlike lifeless nature, means the ability of a substance to organise and reproduce itself only through intrinsic principles and "that in which everything is an end and reciprocally a means as well. Nothing in it is in vain, purposeless, or to be ascribed to a blind mechanism of nature." (Kant, 2000, § 66, pp. 247). So although he stresses the principle of self-organisation, Kant sees a sort of dominating relation ${ }^{39}$ between the whole and its parts (the whole organises its parts for itself).

Such assumptions have become untenable according to the principles of second-order cybernetics. ${ }^{40}$ Neither in biological nor in social systems can an instance claim to have a better, more truthful, more detailed or more exact description of the whole, individual parts or the relation between them. In modern sociology, especially in Luhmann's theory of social systems, this insight is expressed in the notion of a functional differentiation of society. The social sub-systems in modern society are distinguished from one another (and thus respectively for social systems of their own) by performing certain special functions for society as a whole. Their communicative operations are entirely focused on fulfilling such a special function. The economic system observes everything happening in the world from the angle of economic relevance, the legal system from whether laws are breached and the political system from whether issues of power are affected.

Luhmann describes modern society as the result of historical change, as a transformation from a stratificatory to a functional differentiation of society. While enormous hierarchical inequalities exist in the stratificatory society, it could still rely on a uniform semantics. Of course the world appeared to the aristocrat in a different way from how it did to the peasant, but it was nevertheless the same world. This is the only possible explanation for the differences not even being perceived as inequalities - for example in

\footnotetext{
${ }^{38}$ Unlike H.v. Foerster or H. Maturana, Kant did not believe that it is possible to determine life on the basis of the laws of mechanics. Attempts to give an explanation in this manner would tend to overlook precisely the special quality of life, i.e. what distinguishes an organism from a mechanism. Kant maintained that there would never be a "Newton of grass blades" $(2000, \S 75$, p. 271). But it is exactly what Kant doubted that is elevated to the status of a programme by Maturana and others and artificial life research, which is based largely on this proposition.

${ }^{39}$ Aristotle already regards dominance as the medium securing the unity of the whole: “(...) in every composite thing, where a plurality of parts, whether continuous or discrete, in combined to make a single common whole, there is always found a ruling and a subject factor, and this characteristic of living things is present in them as an outcome of the whole of nature, since even in things that do not partake of life, there is a ruling principle, as in the case of a musical scale" (Aristotle 1950, p. 19)

${ }^{40}$ Although Maturana does see the possibility of such subordination, too. However, these are then special cases in which autopoietic systems are treated allopoietically (Maturana and Varela 1985, p. 188).
} 
the sense of injustice. However, this changed radically with the transition to a functional society. The uniform character of hierarchical order explodes into the plurality of a heterarchical order. ${ }^{41}$ Every functional system has its own view of the world that differs from that of other functional systems and cannot be traced back to a common pattern. Now, however, to take up the issue of the relation between stability and instability, this heterarchy by no means indicates a state of disorder. On the contrary, from the angle of each individual system, the relations to the other systems are subject to an order of their own that in turn is subject to the primacy of its own function (Esposito 2002, p. 201).

This results in an enormous increase in contingency (Esposito, 2002, p. 203). A change in the form of observation - that of observing observation - ensures that this does not lead to a collapse of orientation and order (cf. Esposito,222 2002, p. 204).

Whereas some systems theoreticians ${ }^{42}$ continue to regard control as indispensible and here stress the importance of the political system as an institution, Luhmann points to the internal motives of the respective social systems and consistently takes up the previously elaborated cybernetic pattern of argumentation:

"Although there is no possibility to intervene in structural developments from outside, the irritations that a system has to deal with again and again - and also the indifference that it can afford - play an important role" (Luhmann 1997, p. 780) ${ }^{43}$

However, Luhmann sees no convincing indication of the danger of a ruthless juxtaposition or opposition of the functional systems:

"If modern society were merely described as a set of autonomous functional systems that owe each other no consideration but merely follow the reproduction needs of their own autopoeisis, this would yield a highly one-sided picture. It would then be difficult to understand why this society would not explode or disintegrate within a short time" (Luhmann, 1997, p. 776) ${ }^{44}$

Here too, he takes up Maturana's concept of structural coupling but gives it a sociological turn by relating the necessary self-regulatory processes to the impact of regulatory

\footnotetext{
${ }^{41}$ With this order including, however, a multitude of simultaneously existing, equal hierarchies (Esposito, 2002, p. 201)

${ }^{42} \mathrm{cf}$. Helmut Willke, who, however, prefers the term "intervention" regarding the relation between state and society (Willke 1992).

${ }^{43}$ Translated by the author

${ }^{44}$ Translated by the author
} 
media or, in Talcott Parsons' language, to symbolically generalised communication media. Here, highly-condensed information is involved that enables action and communication links in symbolic form without the pre-understanding and motives they are connected with having to be negotiated and co-ordinated anew again and again. Such media serve the purpose of communicating what a system expects of its environment or, in concrete terms, from another system, and they simultaneously provide the motivation for the other system's really fulfilling this expectation of behaviour. In other words, they raise the probability of communication's capability of linking up (connectivity), thus contributing to the success of communication.

In this respect, success media first of all have a symbolic character, i.e. they stand for something (one is prepared to exchange goods or render services provided that they are paid for), and secondly are generalised, i.e. they apply independently of concrete situations. Thanks to these two features, symbolically generalised communication media are capable of performing two things: First of all, they stabilise communicative relations on a lasting basis, thus contributing to the formation of systems. Second, they represent a sort of catalyst for the differentiation of systems. This reduces complexity. Simpler types of system evolve that can concentrate on certain aspects of events in the world. But on the other hand, for the system affected, this leads to a new type of complexity that Luhmann refers to as hypercomplexity. The creation of autonomous sub-systems inevitably results in a multitude of new interfaces between the differentiated autonomous sub-systems (interface complexity), so that new, previously unexpected modes of response now have to be reckoned with.

Social systems are based on communicative operations and therefore primarily on the use of language. In spite of this, the formation and maintenance of systems cannot be attributed solely to the effect of the language medium. For its use simultaneously and generally always entails a threat to the autopoiesis of communication. On the one hand, it is language that enables social understanding in the first place, but on the other, the more precise the use of language becomes, the greater the possibility of divergence and rejection of communicative offers will be (Luhmann, 1989, p. 235). According to Luhmann, that communication can develop at all has to be regarded as something principally improbable. That social systems evolve and stabilise in spite of this improbability can be explained with the effectiveness of symbolically generalised communication media. 


\section{Final note}

The above has shown that the relation to cybernetics not only assumes a very important status for the development of Niklas Luhmann's theory of social systems, but that, conversely, Luhmann's systems theory can be integrated in the range of "new cybernetics" (Geyer and Zouwen 1986) approaches as a type of socio-cybernetic thinking. The list of criteria drawn up at the beginning of this paper that qualify an approach as cybernetic was to serve as a guideline to evaluate the cybernetic content of Luhmann's theory. Luhmann does not eliminate the uncertainty referred to above regarding how systems theory and cybernetics relate to one another either. While preferring to use the term system for his approach, in his definition of concepts, he refers to central controversial aspects of the debate on the relation between the two disciplines at the time. With the adoption of Maturana's concept of autopoiesis, the circularity principle (cf. von Foerster, 1993) assumes a central role in his theory, which can therefore, without any doubt, be qualified as cybernetic. In his systems concept, his notion of the relation between the system and the environment, he follows up largely on modern systems theory literature (Bertalanffy, 1968). What sociology gains through the application of cybernetic principles is a convincing theoretical explanation of the phenomenon of how communication becomes possible in spite of double contingency. This is no more and no less than a satisfactory answer to sociology's fundamental question about social order. Luhmann argues with circular causal feedback principles as a response to communications problems in social systems. And he takes the problem more serious than hardly any other sociologist that heterarchy within regulatory systems, which is stressed by cybernetics (in particular second-order cybernetics) can no longer be described with causal or technical models. While this does not yet represent a socio-cybernetic regulatory theory, it could mark the approach to the direction such a theory would have to be developed in.

\section{References}

Aristotle (1950). Politics (Reprint of the First Edition 1932). (with an English Translation by H. Rackham). London: William Heinemann Ltd.

Ashby, W. Ross (1957). An Introduction to Cybernetics. London: Chapman \& Hall.

Bateson, Gregory (1972). Steps to an Ecology of Mind. New York: Chandler.

Beer, Stafford (1959). Cybernetics and Management. London: English Universities Press.

- (1981). Brain of the firm: the managerial cybernetics of organization. New York: J. Wiley \& Sons. 
Bertalanffy, Ludwig von (1968). General System Theory. Foundations, Development, Applications. New York: Braziller.

Buckley, Walter (1998). Society - A Complex Adaptive System. Essays in Social Theory. Amsterdam: Gordon \& Breach.

De La Mettrie, Julien Offray (1985). Der Mensch als Maschine. Ed. by LSR-Verlag. (Originally published as "L'homme machine, Paris 1748"). Nürnberg.

Durkheim, Emile (1965). Die Regeln der soziologischen Methode. Neuwied - Berlin: Luchterhand.

Ebeling, Werner, Jan Freund, and Frank Schweitzer (1998). Komplexe Strukturen: Entropie und Information. Stuttgart - Leipzig: Teubner.

Esposito, Elena (2002). Soziales Vergessen. Formen und Medien des Gedächtnisses der Gesellschaft. Frankfurt am Main: Suhrkamp.

Foerster, Heinz von (1993a). "Kybernetik". In: Wissen und Gewissen. Ed. by Heinz Von Foerster. Frankfurt am Main: Suhrkamp, pp. 72-76.

- (1993b). Wissen und Gewissen. Versuch einer Brücke. Frankfurt am Main: Suhrkamp.

Friedrich, J., H. Schweizer, and E. Sens (1975). Marxismus und Kybernetik. Philosophische, gesellschaftswissenschaftliche, sprachwissenschaftliche Aspekte. Kronberg/Ts.: Scriptor.

Fuchs, Peter (1993). Moderne Kommunikation. Zur Theorie des operativen Displacements. Frankfurt am Main: Suhrkamp.

Geyer, Felix and Johannes van der Zouwen (1986). Sociocybernetics paradoxes: observation, control and evolution of self-steering systems. London: Sage.

Hegel, Georg Wilhelm Friedrich (1970). Phänomenologie des Geistes. Hegel Werke. Band 3 (1807). Frankfurt am Main: Suhrkamp.

Kant, Immanuel (2000). Critique of the Power of Judgement (1790). (Originally published as "Immanuel Kant: Kritik der Urteilskraft. Königsberg 1790", translated by Paul Guyer and Eric Matthews). Cambridge: Cambridge University Press.

Klaus, Georg (1965). Kybernetik und Gesellschaft. Berlin: Deutscher Verlag der Wissenschaften.

Luhmann, Niklas (1968). Zweckbegriff und Systemrationalität. Über Funktion von Zwecken in sozialen Systemen. Tübingen: Mohr (Siebeck).

- (1972). "Funktionale Methode und Systemtheorie". In: Soziologische Aufklärung. Band 1: Aufsätze zur Theorie sozialer Systeme. Ed. by Niklas Luhmann. Opladen: Westdeutscher Verlag, pp. 31-52.

Luhmann, Niklas (1989). Ecological communication. (Originally published as "Ökologische Kommunikation. Kann die moderne Gesellschaft sich auf ökologische Gefährdun- 
gen einstellen? Opladen: Westdeutscher Verlag, 1986). Chicago: University of Chicago Press.

- (1990). Die Wissenschaft der Gesellschaft. Frankfurt am Main: Suhrkamp.

- (1995). Social Systems. Stanford, CA: Stanford University Press.

- (1997). Die Gesellschaft der Gesellschaft, 2 Bände. Frankfurt am Main: Suhrkamp.

- (2002). Einführung in die Systemtheorie. Herausgegeben von Dirk Baecker. Heidelberg: Carl-Auer-Verlag.

Marc, Edmond and Dominique Picard (2000). L'école de Palo Alto : un nouveau regard sur les relations humaines. Paris: Retz.

Maturana, Humberto R. (1982). "Kognitive Strategien (Cognitive Strategies, 1972)”. In: Erkennen: Die Organisation und Verkörperung von Wirklichkeit. Ed. by Humberto R. Maturana. (Originally published in French as "Maturana, Humberto R.: Stratégies cognitives. In: Morin, E. \& Piatelli-Palmarini, M.: L'unité de l'homme. S. 418-442, Paris, 1975"). Braunschweig und Wiesbaden, pp. 297-318.

Maturana, Humberto R. and Francisco J. Varela (1982). "Autopoietische Systeme: Eine Bestimmung der lebendigen Organisation”. In: Erkennen: Die Organisation und Verkörperung von Wirklichkeit. Ausgewählte Arbeiten zur biologischen Epistemologie. Ed. by Humberto R. Maturana. (Originally published as "Autopoietic Systems. A Characterization of the Living Organisation, Report 9.4, Biological Computer Laboratory, Department of Electrical Engineering, University of Illinois, Urbana-Champaign, Ilinois, USA, 1975"). Braunschweig - Wiesbaden: Vieweg, pp. 170-235.

Shannon, Claude E. (1963). "The Mathematical Theory of Communication". In: The Mathematical Theory of Communication. Ed. by Claude E. Shannon and Warren Weaver. Urbana: University of Illinois, pp. 3-91.

Steinbuch, Karl (1971). Automat und Mensch. Auf dem Weg zu einer kybernetischen Anthropologie. 4. neubearbeitete Auflage. Berlin - Heidelberg - New York: Springer.

Stonier, Tom (1990). Information and the Internal Structure of the Universe. An Exploration into Information Physics. Berlin - Heidelberg - New York: Springer.

Weaver, Warren (1963). "Recent Contributions to the Mathematical Theory of Communication". In: The Mathematical Theory of Communication. Ed. by Claude E. Shannon and Warren Weaver. University of Illunois Press, pp. 94 -117.

Weizsäcker, Carl Friedrich von (1974). Die Einheit der Natur. München.

Wiener, Norbert (1948). Cybernetics or Control and Communication in the Animal and the Machine. New York: J. Wiley.

- (1951). Cybernetics and Society. New York: Executive Techniques. 
Willke, Helmut (1992). Ironie des Staates. Grundlinien einer Theorie des Staates polyzentrischer Gesellschaft. Frankfurt am Main: Suhrkamp. 